\title{
Commentary \\ The mammary myoepithelial cell - Cinderella or ugly sister?
}

Sunil R Lakhani and Michael J O'Hare ${ }^{\dagger}$

*Breast Molecular Pathology Laboratory, Department of Histopathology, Royal Free and University College Medical School, London, UK
+LICR/UCL Breast Cancer Laboratory, Royal Free and University College Medical School, London, UK

Correspondence: Sunil R Lakhani, Breast Molecular Pathology Laboratory, Department of Histopathology, Royal Free and University College Medical School, University College London, Rockefeller Building, University Street, London WC1E 6JJ, UK. Tel: +44 207679 6019; fax: +44 20 7387 3674; e-mail: s.lakhani@ucl.ac.uk

Received: 15 September 2000

Accepted: 26 September 2000

Published: 2 November 2000
Breast Cancer Res 2001, 3:1-4

(C) BioMed Central Ltd on behalf of the copyright holder (Print ISSN 1465-5411; Online ISSN 1465-542X)

\begin{abstract}
The breast myoepithelial cell is the Cinderella of mammary biology. Although its contribution to benign and some malignant pathologies is recognised, it has been largely neglected in molecular and biological studies. The reason for this has been the perception that its role in normal physiology is confined to lactation and the belief that most breast cancers arise from luminal epithelial cells. This review presents our perspective on its broader biological significance and its potential use as a model system for understanding breast carcinogenesis.
\end{abstract}

Keywords: breast, breast cancer, cell biology, myoepithelial, pathology

\section{Introduction}

Two epithelial cell types, present in roughly equal numbers, line the entire normal duct and lobular system of the human breast. There is an inner 'luminal' or 'secretory' cell layer and an incomplete outer myoepithelial cell layer. Since the myoepithelium is incomplete, some luminal cells reach the basement membrane. The myoepithelial cells, in contrast, do not reach the luminal surface. The myoepithelial cells are attached to the basement membrane by hemidesmosomes and to the adjacent luminal cells by desmosomes. The cells have pinocytic vesicles, containing microfilaments and dense bodies resembling smooth muscle. The myofilaments are not as well developed in the cells lining the acini compared with those lining the terminal ducts and the interlobular ducts. The myoepithelial cell is, in some respects, the Cinderella of the breast. It has been largely ignored in the context of breast cancer. Although the cell's auxiliary role in lactational physiology is well recognised, this is a minor component of the process and is limited to assisting milk ejection during suckling in response of oxytocin. What, however, of the other $99 \%$ of time? Those with a more philosophical bent have found it hard to believe that the contractile function represents the be all and end all of myoepithelial cell function.

Its position, interposed between stroma and lumen, places it in an ideal situation to control many aspects of luminal function. It could regulate polarity, electrolyte and fluid flow, filter and process signals of endocrine or paracrine nature, and perhaps act as an intermediary in such signalling processes by passing information both inwards and outwards in a paracrine fashion or via intra-epithelial gap-junctions [1]. One school of thought has indeed invested the myoepithelium with great significance as a paracrine inhibitor of invasion and thus an inhibitor of tumour progression [2]. Other workers have proposed that, in the absence of fully differentiated myoepithelial cells, a failure to sequester local growth factor such as $\beta$-fibroblast growth factor may contribute to uncontrolled growth of malignant breast cells [3]. That said, there is only limited direct experimental information that addresses these hypotheses [2,4-6]. Perhaps the most convincing experiment would

NOS = no special type. 
be removal of the myoepithelium either by gene knockout or by targeted chemotherapeutic ablation, in a manner similar to that described for the luminal compartment [7]. Many key genes undoubtedly impact on myoepithelial function but, if deletions are lethal at early stages of embryonic or postpartum life, then their effects on mature myoepithelial function cannot be assessed. In this context, the transgenic fat-pad model $[8,9]$ and the rarely used xenograft model [10] could be useful experimental tools if combined with appropriate cell separation techniques.

We and other workers have developed methods to separate pure populations of luminal and myoepithelial cells from the mouse [11], the rat [12,13] and, most importantly, from humans [14-16]. These methods give us, in principle, the means to analyse the role of the myoepithelial cell in detail, at least in vitro. In practice, no group has exploited this with vigour, due in part to an emphasis on comparing luminal cells with invasive cancer, discarding the myoepithelial cells as an unwanted contaminant. This is also due to the fact that the essential contractile aspect of myoepithelial function, in the form of organised myofilaments, is progressively lost under conventional culture conditions in human, rat and mouse cells $[11,12,14]$. The human myoepithelial cells do, however, retain a basal phenotype that is stable, retained during cloning, and that allows them to be readily distinguished from luminal cells. The use of complex culture environments such as extracellular matrix-containing substrates can delay or reduce this 'de-differentiation' to some extent [17]. However, there is no disguising the fact that, once they have been separated and introduced into long-term culture, myoepithelial cells are but a shadow of their former selves. It is perhaps understandable under these circumstances that no great effort has been made in analysing their detailed physiology. There is an urgent need for more short-term culture experiments involving separation and controlled recombination of the major breast cell types in order to reveal their functions and interactions in the non-lactating mammary gland. As a step in this direction, a highly detailed analysis of the patterns of protein expression from freshly separated human luminal and myoepithelial cells has been completed recently using proteomic technology [18].

A major enigma in myoepithelial biology and pathobiology is the apparent infrequency with which this cell type gives rise to tumours. The cells are an integral part of benign lesions such as sclerosing adenosis and papillomata. Their contribution to breast malignancy has been unclear. Tumours showing myoepithelial differentiation have been reported more frequently in the past 20 years and include adenoid cystic carcinoma, adenosquamous carcinoma, adenomyoepithelioma, pure myoepithelial carcinoma and poorly differentiated myoepithelial rich carcinoma [19-21]. These tumours appear to be rare in clinical practice [22] and reports in the literature are generally of small series or isolated case reports [20,22-24]. The contribution of myoepithelial cells to ordinary ductal carcinomas is also unclear and reports suggest that $2-18 \%$ of so-called ductal carcinomas-no special type (NOS) show focal or diffuse myoepithelial differentiation by immunohistochemical criteria (eg basal cytokeratins, actin, calponin, caldesmon, S100 protein) [25-27].

As part of our investigation of genetic changes in pre-invasive breast disease, we have shown that loss of heterozygosity identified in invasive cancer is already present independently in 'normal' luminal and myoepithelial cells [28]. This suggests that there was a common precursor cell that acquired the mutation prior to differentiation into the two epithelial cell types. Some cells within the lobules are difficult to categorise, morphologically and ultrastructurally, into luminal or myoepithelial and it has been suggested that these 'intermediate' or 'indeterminate' cells are the precursors of the two epithelial cell types. It therefore seems odd that tumours exhibiting myoepithelial differentiation should be so rare in clinical practice; in contrast, for example, to the salivary gland.

The morphology of myoepithelial carcinomas is different to tumours derived from luminal cells. The myoepithelial carcinomas resemble sarcomas by having a predominantly spindle cell growth pattern $[20,23]$. Although there are only a few reports in the literature, approximately $50 \%$ of the published cases followed an aggressive course [20]. We carried out comparative genomic hybridisation analysis on 10 pure myoepithelial carcinomas [29] and compared the data with that of ductal carcinomas-NOS. The most striking observation was the paucity of alterations in myoepithelial carcinomas (mean, 2.1) compared with 'ordinary' breast carcinomas with luminal differentiation (mean, 5.4 in Grade I; mean, 11.7 in Grade III) [30-34]. The data are especially surprising in view of the aggressive morphology and behaviour of myoepithelial carcinomas. Seven out of 10 tumours were larger than $2 \mathrm{~cm}$ in size and four out of seven patients for whom follow-up information was available had died within 6 years of diagnosis. None of the alterations identified in myoepithelial carcinomas were unique, and they have been previously described in invasive breast carcinomas with luminal phenotype [30-34]. Although there was considerable overlap in the genetic profile of the two distinct epithelial tumour types, some of the most common alterations described in ductal carcinomas, such as gains of $1 q, 8 q$ and $20 q$, and losses of $1 p, 8 p$ and $13 q$ [30-34], were not identified in myoepithelial carcinomas. On the assumption that the two cell types are derived from a common precursor cell [28], genetic alterations that overlap between luminal and myoepithelial tumours must have occurred within precursor cells prior to differentiation into the two epithelial cell types. Those alterations, which do not overlap, would have to occur subsequent to differentiation. We had, in one of our cases, the opportunity to 
investigate this fact, as ductal carcinoma and myoepithelial carcinoma was present within the same tissue block. Loss at $17 p$ was seen in both tumour types. Only one other alteration was seen in the myoepithelial tumour, while the ductal carcinoma showed 13 other alterations. We would therefore hypothesise that loss at $17 p$ occurred within a 'stem cell/precursor cell', while alterations at other loci occurred subsequent to differentiation into the two epithelial cell types. We cannot formally exclude the possibility that the myoepithelial cell with $17 p$ loss was derived from the luminal cell, as has been suggested recently [35]. However, unlike some other laboratories [36], we interpret our own extensive studies of separated luminal and myoepithelial cells in vitro as showing no evidence of any lability or interchangeability between the two basic epithelial cell types, either in bulk culture or as clones. We believe that the enhanced proliferative potential of the cultured human myoepithelial cell is the likely source of apparent heterogeneity in established cultures.

Since invasive ductal carcinomas exhibit a large number of alterations, it has been difficult to differentiate between pathogenic mutations and non-specific mutations due to genomic instability. Myoepithelial cells, in contrast, appear resistant to transformation, and myoepithelial carcinomas exhibit few genetic alterations. Since the alterations identified in myoepithelial carcinomas are also those seen in ductal carcinomas, these alterations are likely to be pathogenetically significant in breast carcinogenesis. The relatively few genetic alterations in otherwise aggressive neoplasms lead us to propose that myoepithelial tumours may be a better model than ductal carcinomas-NOS for the delineation of genes important in breast tumorigenesis. These data also provide a tool with which to investigate the significance of apparent myoepithelial differentiation in morphologically ductal carcinoma-NOS. The presence of specific genetic changes should discriminate between entrapped non-malignant cells and true tumour cells showing myoepithelial differentiation. Furthermore, the patterns of such changes, if present, could throw light on the clonal evolution within such cancers.

There is no doubt, even allowing for under-recognition of the contribution of myoepithelial cells to breast cancer, that the cells represent less than one-fifth of all cancers. The possible reasons for the resistance to transformation of this cell range from the simplistic to the untestable. As a relatively mitotically quiescent cell [37], it may simply not be as susceptible to tumorigenesis as the cycling luminal cell. Alternatively, or in addition, it could possess a greater DNA repair capacity, a hypothesis that is directly testable using separated cells. Another possibility is that myoepithelial cells express a greater range of tumour suppressor functions that need to be inactivated before a malignant phenotype is acquired. However, this seems unlikely in light of the data from our laboratory [29] that myoepithelial carcinomas, which are generally aggressive, show fewer genetic alterations. The low proliferation index of the myoepithelium in adult humans highlights another extraordinary feature of its behaviour. Studies with separated human cells have shown that, in vitro, myoepithelial cells can re-enter the cell cycle very rapidly and proliferate very fast [14]. As clones can be obtained from at least $50 \%$ of such separated cells, this is clearly not a property of rare stem cells, but extends to the majority of the functionally differentiated cells. This potential proliferative capacity emphasises the paradox of their failure to transform because they are clearly not a permanently postmitotic population. The presence of cycling cells of this phenotype in the pregnant human breast [38] further attests to their innate proliferative potential. Their proliferation in vitro has, in a practical context, caused much grief in studies of unseparated breast epithelial cells, the culture of tumour samples, many of which are still surrounded by myoepithelial cells, and in the spontaneous or engineered establishment of cell strains and lines. Some of the latter, which purport to be the appropriate controls for breast malignancy, express basal rather than luminal characteristics, including basal cytokeratins and specialised junctional proteins such as hemidesmosome components. It is fascinating but appalling to observe such differences being highlighted in complex transcriptional profiling experiments [39] without the penny dropping! The advent of improved methods of human cell immortalisation, combined with the use of pre-separated characterised cells, does enable more appropriate cell line models to be developed [40]. Matched pairs of luminal and myoepithelially derived lines can also be developed for further investigation of normal functional interactions. The reproducible development of similar lines from malignant breast epithelial cells, be they luminal or myoepithelial in phenotype, remains a major challenge of breast tumour biology and pathology.

\section{Conclusion}

The myoepithelial cell is the Cinderella rather than the ugly sister of mammary cell biology. Its role and potential have been under-recognised. We believe that it will play an increasingly important part in delineating and understanding the events in breast physiology and pathology.

\section{References}

1. Locke D, Perusinghe N, Newman T, Jayatilake H, Evans WH, Monaghan P: Developmental expression and assembly of connexins into homomeric and heteromeric gap junction hemichannels in the mouse mammary gland. J Cell Physiol 2000, 183:228-237.

2. Sternlicht MD, Kedeshian P, Shao ZM, Safarians S, Barsky SH: The human myoepithelial cell is a natural tumor suppressor. Clin Cancer Res 1997, 3:1949-1958.

3. Rudland PS, Fernig DG, Smith JA: Growth factors and their receptors in neoplastic mammary glands. Biomed Pharmacother 1995, 49:389-399.

4. Shao ZM, Nguyen M, Alpaugh ML, O'Connell JT, Barsky SH: The human myoepithelial cell exerts antiproliferative effects on breast carcinoma cells characterized by p21WAF1/CIP1 induction, G2/M arrest, and apoptosis. Exp Cell Res 1998, 241:394-403. 
5. Gomm JJ, Browne PJ, Coope RC, Bansal GS, Yiangou C, Johnston CL, Mason R, Coombes RC: A paracrine role for myoepithelial cell-derived FGF2 in the normal human breast. Exp Cell Res 1997, 234:165-173.

6. Slade MJ, Coope RC, Gomm JJ, Coombes RC: The human mammary gland basement membrane is integral to the polarity of luminal epithelial cells. Exp Cell Res 1999, 247:267-278.

7. Clark AJ, Iwobi M, Cui W, Crompton M, Harold G, Hobbs S, Kamalati T, Knox R, Neil C, Yull F, Gusterson B: Selective cell ablation in transgenic mice expression $E$. coli nitroreductase. Gene Ther 1997, 4:101-110.

8. Edwards PA: Control of the three-dimensional growth pattern of mammary epithelium: role of genes of the Wnt and erbB families studied using reconstituted epithelium. Biochem Soc Symp 1998, 63:21-34.

9. Fantl V, Edwards PA, Steel JH, Vonderhaar BK, Dickson C: Impaired mammary gland development in Cyl-1(-/-) mice during pregnancy and lactation is epithelial cell autonomous. Dev Biol 1999, 212:1-11.

10. Dubois JD, O'Hare MJ, Monaghan P, Bartek J, Norris R, Gusterson BA: Human breast epithelial xenografts: an immunocytochemical and ultrastructural study of differentiation and lactogenic response. Differentiation 1987, 35:72-82.

11. Smalley MJ, Titley J, O'Hare MJ: Clonal characterization of mouse mammary luminal epithelial and myoepithelial cells separated by fluorescence-activated cell sorting. In Vitro Cell Dev Biol Anim 1998, 34:711-721.

12. Dundas SR, Ormerod MG, Gusterson BA, O'Hare MJ: Characterization of luminal and basal cells flow-sorted from the adult rat mammary parenchyma. J Cell Sci 1991, 100 (part 3): 459-471.

13. Wojcik SF, Capen CC, Rosol TJ: Expression of PTHrP and the PTH/PTHrP receptor in purified alveolar epithelial cells, myoepithelial cells, and stromal fibroblasts derived from the lactating rat mammary gland. Exp Cell Res 1999, 248:415422.

14. O'Hare MJ, Ormerod MG, Monaghan P, Lane EB, Gusterson BA: Characterization in vitro of luminal and myoepithelial cells isolated from the human mammary gland by cell sorting. Differentiation 1991, 46:209-221.

15. Clarke C, Titley J, Davies S, O'Hare MJ: An immunomagnetic separation method using superparamagnetic (MACS) beads for large-scale purification of human mammary luminal and myoepithelial cells. Epithelial Cell Biol 1994, 3:38-46.

16. Gomm JJ, Browne PJ, Coope RC, Liu QY, Buluwela L, Coombes $\mathrm{RC}$ : Isolation of pure populations of epithelial and myoepithelial cells from the normal human mammary gland using immunomagnetic separation with Dynabeads. Anal Biochem 1995, 226:91-99.

17. Smalley MJ, Titley J, Paterson H, Perusinghe N, Clarke C, O'Hare $\mathrm{MJ}$ : Differentiation of separated mouse mammary luminal epithelial and myoepithelial cells cultured on EHS matrix analyzed by indirect immunofluorescence of cytoskeletal antigens. J Histochem Cytochem 1999, 47:1513-1524.

18. Page MJ, Amess B, Townsend RR, Parekh R, Herath A, Brusten L, Zvelebil MJ, Stein RC, Waterfield MD, Davies SC, O'Hare MJ: Proteomic definition of normal human luminal and myoepithelial breast cells purified from reduction mammoplasties. Proc Natl Acad Sci USA 1999, 96:12589-12594.

19. Tavassoli FA: Myoepithelial lesions of the breast. Myoepitheliosis, adenomyoepithelioma, and myoepithelial carcinoma. Am J Surg Pathol 1991, 15:554-568.

20. Foschini MP, Eusebi V: Carcinomas of the breast showing myoepithelial cell differentiation. A review of the literature. Virchows Arch 1998, 432:303-310.

21. Damiani S, Riccioni L, Pasquinelli G, Eusebi V: Poorly differentiated myoepithelial cell rich carcinoma of the breast. Histopathology 1997, 30:542-548.

22. Eusebi V, Casadei GP, Bussolati G, Azzopardi JG: Adenomyoepithelioma of the breast with a distinctive type of apocrine adenosis. Histopathology 1987, 11:305-315.

23. Lakhani SR, O'Hare MJ, Monaghan P, Winehouse J, Gazet JC Sloane JP: Malignant myoepithelioma (myoepithelial carcinoma) of the breast: a detailed cytokeratin study. J Clin Pathol 1995, 48:164-167.

24. Thorner PS, Kahn HJ, Baumal R, Lee K, Moffatt W: Malignant myoepithelioma of the breast. An immunohistochemical study by light and electron microscopy. Cancer 1986, 57 $745-750$.

25. Guelstein VI, Tchypysheva TA, Ermilova VD, Litvinova LV, Troyanovsky SM, Bannikov GA: Monoclonal antibody mapping of keratins 8 and 17 and of vimentin in normal human mammary gland, benign tumors, dysplasias and breast cancer. Int J Cancer 1988, 42:147-153.

26. Gusterson BA, Warburton MJ, Mitchell D, Ellison M, Neville AM, Rudland PS: Distribution of myoepithelial cells and basement membrane proteins in the normal breast and in benign and malignant breast diseases. Cancer Res 1982, 42:4763-4770.

27. Nagle RB, Bocker W, Davis JR, Heid HW, Kaufmann M, Lucas DO, Jarasch ED: Characterization of breast carcinomas by two monoclonal antibodies distinguishing myoepithelial from luminal epithelial cells. J Histochem Cytochem 1986, 34: 869-881.

28. Lakhani SR, Chaggar R, Davies S, Jones C, Collins N, Odel C, Stratton MR, O'Hare MJ: Genetic alterations in 'normal' luminal and myoepithelial cells of the breast. J Pathol 1999, 189: 496-503.

29. Jones C, Foschini MP, Chaggar R, Lu YJ, Wells D, Shipley JM, Eusebi V, Lakhani SR: Comparative genomic hybridization analysis of myoepithelial carcinoma of the breast. Lab Invest 2000, 80:831-836.

30. Buerger H, Otterbach F, Simon R, Schafer KL, Poremba C, Diallo $\mathrm{R}$, Brinkschmidt C, Dockhorn-Dworniczak B, Boecker W: Different genetic pathways in the evolution of invasive breast cancer are associated with distinct morphological subtypes. $J$ Pathol 1999, 189:521-526.

31. Nishizaki T, DeVries S, Chew K, Goodson WH 3rd, Ljung BM, Thor A, Waldman FM: Genetic alterations in primary breast cancers and their metastases: direct comparison using modified comparative genomic hybridization. Genes Chromosomes Cancer 1997, 19:267-272.

32. Roylance R, Gorman P, Harris W, Liebmann R, Barnes D, Hanby A, Sheer D: Comparative genomic hybridization of breast tumors stratified by histological grade reveals new insights into the biological progression of breast cancer. Cancer Res 1999, 59:1433-1436.

33. Schwendel A, Richard $F$, Langreck $H$, Kaufmann $O$, Lage $H$, Winzer KJ, Petersen I, Dietel M: Chromosome alterations in breast carcinomas: frequent involvement of DNA losses including chromosomes 4q and 21q. Br J Cancer 1998, 78: 806-811.

34. Tirkkonen M, Tanner M, Karhu R, Kallioniemi A, Isola J, Kallioniemi OP: Molecular cytogenetics of primary breast cancer by $\mathrm{CGH}$. Genes Chromosomes Cancer 1998, 21:177-184.

35. Petersen OW, Ronnov-Jessen L, Weaver VM, Bissell MJ: Differentiation and cancer in the mammary gland: shedding light on an old dichotomy. Adv Cancer Res 1998, 75:135-161.

36. Pechoux C, Gudjonsson T, Ronnov-Jessen L, Bissell MJ, Petersen OW: Human mammary luminal epithelial cells contain progenitors to myoepithelial cells. Dev Biol 1999, 206:88-99.

37. Joshi K, Smith JA, Perusinghe N, Monoghan P: Cell proliferation in the human mammary epithelium. Differential contribution by epithelial and myoepithelial cells. Am J Pathol 1986, 124: 199-206.

38. Suzuki R, Atherton AJ, O'Hare MJ, Entwistle A, Lakhani SR, Clarke $\mathrm{C}$ : Proliferation and differentiation in the human breast during pregnancy. Differentiation 2000, 66:106-115.

39. Nacht M, Ferguson AT, Zhang W, Petroziello JM, Cook BP, Gao $\mathrm{YH}$, Maguire S, Riley D, Coppola G, Landes GM, Madden SL, Sukumar $S$ : Combining serial analysis of gene expression and array technologies to identify genes differentially expressed in breast cancer. Cancer Res 1999, 59:5464-5470.

40. Harris RA, Eichholtz TJ, Hiles ID, Page MJ, O'Hare MJ: New model of ErbB-2 over-expression in human mammary luminal epithelial cells. Int J Cancer 1999, 80:477-484. 